\title{
Empathy and burnout: a study on residents from a Singapore institution
}

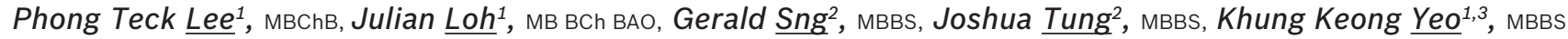

\begin{abstract}
INTRODUCTION Empathy and burnout are two entities that are important in a physician's career. They are likely to relate to each other and can be heavily influenced by surrounding factors, such as medical education, local practices and cultural expectations. To our knowledge, empathy and burnout studies have not been performed in Singapore. This study was designed to evaluate empathy and burnout levels using the Jefferson Scale of Physician Empathy (JSPE) and Maslach Burnout Inventory (MBI) among residents in Singapore, and compare them with the United States (US) literature.

METHODS The JSPE, MBI and a self-designed questionnaire were completed by 446 trainees at a residency-sponsoring institution in Singapore.

RESULTS Residents in Singapore had lower empathy and higher rates of burnout compared to US literature. Physician empathy was associated with burnout: residents with higher empathy scores had higher personal accomplishment $\left(p<0.001, r=0.477, r^{2}=0.200\right)$; and lower emotional exhaustion $\left(p<0.001, r=0.187, r^{2}=0.035\right)$ and depersonalisation $\left(p<0.001, r=0.321, r^{2}=0.103\right)$ scores.

CONCLUSION Residents in Singapore had lower empathy and higher burnout scores compared to the US literature. Further research into the underlying cause is imperative to guide intervention.
\end{abstract}

Keywords: burnout, physician empathy

\section{INTRODUCTION}

Physician empathy is a cognitive attribute that involves the ability to understand a patient's inner experiences, feelings and concerns, combined with an ability to communicate this understanding and an intention to help. (1) Empathy is an innate characteristic that develops from an early age. ${ }^{(2)}$ Physicians who are highly empathetic tend to display multiple positive attributes, such as dutifulness, moral reasoning and clinical competence, ${ }^{(3)}$ as well as better outcomes, such as lower rates of malpractice litigation, ${ }^{(4)}$ enhanced patient satisfaction, ${ }^{(4,5)}$ better physicianpatient relationships ${ }^{(6)}$ and, ultimately, better clinical outcomes. ${ }^{(7)}$ Physician empathy may fluctuate over time and is influenced by working conditions and circumstances.

Studies have recognised that many physicians experience professional burnout, as characterised by loss of enthusiasm toward their work (emotional exhaustion [EE]), feelings of cynicism (depersonalisation [DP]) and a low sense of personal accomplishment (PA). ${ }^{(8-10)}$ Resident burnout is a major problem, and burnout prevalence rates among United States (US) residents have been found to be in the range of $47 \%-70 \%{ }^{(11-13)} \mathrm{High}$ levels of burnout is an issue that can be detrimental to clinical practice, eroding professionalism, influencing quality of care and increasing risk of medical errors. ${ }^{\left({ }^{9}\right)}$ On a personal level, burnout may also contribute to broken relationships ${ }^{(14)}$ and mental health issues, such as substance abuse and suicidal tendencies. ${ }^{(15)}$

The relationship between empathy and burnout is complex and has been studied previously. There is evidence that burnout hampers empathy. Physicians who experience exhaustion and burnout are often depersonalised in social interactions and less capable of demonstrating empathy, such as standing in the patient's shoes and listening empathetically. ${ }^{(16,17)}$ Interestingly, the reverse effect of empathy on burnout is less clear. Studies have demonstrated that empathy can create as well as prevent burnout. 'Compassion fatigue' is an example of how over-relating to a patient's suffering may lead to emotional exhaustion among physicians. ${ }^{(18)}$ On the other hand, empathy is often associated with job satisfaction, which protects physicians from emotional exhaustion. ${ }^{(19)}$ Again, to the best of our knowledge, the association between empathy and burnout has not been studied in Singapore.

Singapore is a modern society that is highly competitive, with long working hours and high job stress. Moreover, traditional values in society and its expectations of physicians may lead to excessive emotional exhaustion and physician burnout. Medical students in Singapore have been shown to be less empathetic than their counterparts from the US, although they were relatively more empathetic compared to counterparts from East Asia. ${ }^{(20)}$ Similarly, nurses in Singapore have intermediate levels of burnout when compared to their peers from China or the United Kingdom (UK). ${ }^{(21)}$ Singapore likely represents a middle ground, with a confluence of Eastern and Western cultures, and is a unique context to evaluate empathy and burnout. ${ }^{(20)}$ This study was conducted to evaluate empathy and burnout among residents in Singapore. We hypothesised that residents in Singapore have high levels of burnout and low levels of empathy compared to the US literature. 


\section{METHODS}

Our cross-sectional study cohort included 446 residents from SingHealth Residency, out of the 879 eligible residents at the time of the survey. Residents were from 34 different programmes and training sites that spanned three general hospitals (Singapore General Hospital, KK Women's and Children's Hospital and Changi General Hospital), five National Specialty Centres and nine community clinics in Singapore.

We used the Jefferson Scale of Physician Empathy for physicians and health professionals (JSPE-HP; referred to as JSPE henceforth ${ }^{(1,22)}$ and Maslach Burnout Inventory-Human Services Survey version, distributed by Mind Garden $\odot$ (MBIHSS; referred to as MBI henceforth), ${ }^{(23,24)}$ as tools to measure empathy and burnout levels, respectively. We have previously published findings on the validity and reliability of the JSPE in Singapore. ${ }^{(20)}$ The JSPE included 20 Likert-type items answered on a 7 -point scale ( 1 = strongly disagree; 7 = strongly agree) with a possible score range of 20-140. The tool incorporates three factors: perspective-taking, compassionate care and standing in the patient's shoes. This is consistent with the concept of a multidimensionality notion of empathy. ${ }^{(25)}$ The MBI included 22 Likert-type items answered on a 6-point scale, which is subdivided into three scales: emotional exhaustion (EE; nine items intended to measure EE; possible score range 0-54); depersonalisation (DP; five items intended to measure perceptions of impersonal, nonappreciative responses by others for providing services or help; possible score range 0-30); and personal accomplishment (PA; eight items measuring perceptions of competence, and successful academic and professional achievement; possible score range 0-48). Clinically significant burnout was defined as having a high subscore on any subscale. ${ }^{(23)}$ We also incorporated a self-designed questionnaire, which included basic demographic information and 21 Likert-type items answered on a 5-point scale to measure structural and personal factors that affected participants' residency training (Appendix).

The study was given an institutional review board waiver by the SingHealth Centralised Institutional Review Board. It was conducted over a five-month period between 1 January 2015 and 31 May 2015. The questionnaire was administered online, as a packet of three instruments (JSPE, MBI and self-designed questionnaire), via the New Innovations client (New Innovations Inc, Uniontown, $\mathrm{OH}$, USA). Two weekly email reminders were sent to non-respondents.

Participation was voluntary and residents' information was anonymised with a coded identifier. An information technology analyst and a programme executive who were not involved in data analysis maintained the master list. The data was password-protected.

Statistical analyses were performed using IBM SPSS Statistics version 20.0 (IBM Corp, Armonk, NY, USA). Cronbach's alpha was calculated to evaluate the internal consistency reliability of the tool. The JSPE scores of respondents were analysed by year of residency using analysis of variance with Bonferroni correction. Gender, specialty choice, marital status, alcohol use and employment of domestic help were analysed using two-tailed $t$-tests. Linear regression was used to examine the relationship between empathy and the individual burnout components of the MBI.

\section{RESULTS}

Of the 879 eligible residents, 446 (50.7\%) volunteered and completed the self-assessment questionnaire. The demographic characteristics for this sample are shown in Table I. Mean age of the residents was $29.4 \pm 2.60$ years. Although there were significantly more eligible residents at the earlier stages of training, the percentage of participation in each year of residency was comparable. The ratio of medical residents to surgical residents was approximately 3:1 and gender numbers were evenly distributed.

Table I. Baseline characteristics of enrolled residents $(n=446)$.

\begin{tabular}{|c|c|}
\hline Variable & No. (\%) \\
\hline Age $(y r)^{*}$ & $29.4 \pm 2.60$ \\
\hline \multicolumn{2}{|l|}{ Year of residency ${ }^{+}$} \\
\hline $\mathrm{R} 1$ & $121 / 280(43.2)$ \\
\hline R2 & $129 / 204(63.2)$ \\
\hline R3 & $91 / 180(50.6)$ \\
\hline R4 & $79 / 142(55.6)$ \\
\hline R5 & $26 / 73(35.6)$ \\
\hline \multicolumn{2}{|l|}{ Clinical specialty ${ }^{+}$} \\
\hline Medical & $333 / 590(56.4)$ \\
\hline Surgical & $113 / 289(39.1)$ \\
\hline \multicolumn{2}{|l|}{ Gender $^{+}$} \\
\hline Men & $212 / 455(46.6)$ \\
\hline Women & $234 / 424(55.2)$ \\
\hline \multicolumn{2}{|l|}{ Ethnicity } \\
\hline Chinese & $386(86.5)$ \\
\hline Malay & $9(2.0)$ \\
\hline Indian & $36(8.1)$ \\
\hline Other & $15(3.4)$ \\
\hline \multicolumn{2}{|l|}{ Marital status } \\
\hline Married & $165(37.0)$ \\
\hline Single & $280(62.8)$ \\
\hline Divorced & $1(0.2)$ \\
\hline \multicolumn{2}{|l|}{ No. of children } \\
\hline 0 & 361 (80.9) \\
\hline 1 & $54(12.1)$ \\
\hline 2 & $20(4.5)$ \\
\hline 3 & $6(1.3)$ \\
\hline$\geq 4$ & $5(1.1)$ \\
\hline \multicolumn{2}{|l|}{ Employment of domestic help } \\
\hline Yes & $142(31.8)$ \\
\hline No & $304(68.2)$ \\
\hline \multicolumn{2}{|l|}{ Alcohol use } \\
\hline Yes & $203(45.5)$ \\
\hline No & $243(54.5)$ \\
\hline Rate of burnout (EE, DP or PA)* & $360(80.7)$ \\
\hline
\end{tabular}

*Data presented as mean \pm standard deviation. +Data presented as no. of participants/no. of total eligible residents $(n=879)$. $\ddagger$ Compared against criteria for burnout as specified by Maslach et al.(23) DP: depersonalisation; EE: emotional exhaustion; PA: personal accomplishment 
Table II. JSPE score, MBI and individual factors in the construct of empathy and burnout for residents.

\begin{tabular}{|c|c|c|c|c|c|c|c|}
\hline \multirow[t]{2}{*}{ Variable } & \multicolumn{5}{|c|}{ Mean \pm standard deviation } & \multirow[t]{2}{*}{ Mean } & \multirow[t]{2}{*}{ Sig } \\
\hline & R1 & $\mathbf{R 2}$ & R3 & R4 & R5 & & \\
\hline JSPE & $104.2 \pm 15.0$ & $105.4 \pm 13.3$ & $106.2 \pm 12.7$ & $103.7 \pm 12.9$ & $104.1 \pm 9.9$ & $104.9 \pm 13.2$ & 0.72 \\
\hline Perspective-taking & $51.2 \pm 9.0$ & $51.7 \pm 8.1$ & $51.8 \pm 8.7$ & $50.9 \pm 8.0$ & $51.2 \pm 7.9$ & $51.4 \pm 8.4$ & 0.95 \\
\hline Compassionate care & $39.0 \pm 5.7$ & $39.4 \pm 5.2$ & $40.2 \pm 4.8$ & $39.2 \pm 5.4$ & $40.4 \pm 4.5$ & $39.5 \pm 5.3$ & 0.47 \\
\hline Standing in patient's shoes & $10.4 \pm 2.2$ & $10.5 \pm 2.1$ & $10.7 \pm 1.8$ & $10.4 \pm 1.9$ & $10.4 \pm 1.9$ & $10.5 \pm 2.0$ & 0.89 \\
\hline Emotional exhaustion & $33.3 \pm 7.8$ & $33.7 \pm 7.6$ & $34.9 \pm 7.5$ & $34.8 \pm 8.1$ & $35.2 \pm 7.3$ & $34.1 \pm 11.2$ & 0.47 \\
\hline Depersonalisation & $15.6 \pm 5.6$ & $14.5 \pm 5.9$ & $15.8 \pm 7.0$ & $15.1 \pm 6.0$ & $14.9 \pm 6.4$ & $15.2 \pm 6.1$ & 0.08 \\
\hline Personal accomplishment & $38.9 \pm 10.7$ & $39.2 \pm 10.9$ & $40.1 \pm 11.9$ & $39.4 \pm 12.0$ & $40.6 \pm 10.6$ & $39.4 \pm 7.7$ & 0.69 \\
\hline
\end{tabular}

JSPE: Jefferson Scale of Physician Empathy; MBI: Maslach Burnout Inventory; R: residency year; Sig: significance

Cronbach's alpha coefficient for the JSPE was 0.870, while that for the MBI was 0.848 . This demonstrated that both tools had an acceptable level of internal consistency and reliability. The overall mean JSPE score for our cohort was $104.9 \pm 13.2$. We did not observe significant differences in overall JSPE empathy scores, or its individual subsets, between residents at different years of training (Table II). This suggested that the empathy construct in our cohort remained stable throughout residency training.

As measured by the $\mathrm{MBI}$, mean scores of $\mathrm{EE}, \mathrm{DP}$ and PA were $34.1 \pm 11.2,15.2 \pm 6.1$ and $39.4 \pm 7.7$, respectively. Maslach et al described high rates of burnout among physicians as scores of $\mathrm{EE} \geq 27, \mathrm{DP} \geq 11$ and $\mathrm{PA} \leq 33$. $^{(23)}$ Using this reference range, we found that 360 out of $446(80.7 \%)$ residents had burnout in at least one of the domains. Similar to the empathy scores, there were no significant differences in the rates of burnout and its components between residents at different years of training (Table II).

Residents with higher empathy scores were associated with lower EE $\left(p<0.001, r=0.187, r^{2}=0.035\right)$ and DP $(p<0.001$, $\left.r=0.321, r^{2}=0.103\right)$, and higher PA $(p<0.001, r=0.477$, $\left.r^{2}=0.200\right)$. For every unit increase in JSPE, there was a 0.158 -point and 0.149-point decrease in EE and DP, respectively, and 0.26-point increase in PA.

\section{DISCUSSION}

The main objectives of this study were to: (a) assess the levels of empathy and burnout among residents in Singapore; and (b) compare findings with the US literature. Our findings suggested that residents in Singapore have lower empathy and higher rates of burnout compared to US studies. The mean empathy score for our cohort was $104.9 \pm 13.2$, which was lower than that of physicians in the US (empathy score $120 \pm 15.6$ ). ${ }^{(1)}$ Rates of burnout and mean $\mathrm{MBI}$ scores were also significantly higher than those in the published data. ${ }^{(8,26)}$ The prevalence of burnout in our cohort was $80.7 \%$, significantly higher than in the US (range $47 \%-70 \%) .{ }^{(11-13)}$ Mean burnout scores in our cohort (EE: $34.1 \pm 11.2$; DP: $15.2 \pm 6.1$; PA: $39.4 \pm 7.7$ ) were also significantly higher than the respective median US scores (EE 21.0; DP 5.0; PA 42.0). ${ }^{(8)}$

Our findings also suggest that physician empathy was correlated with burnout. Among the three subscales of the $\mathrm{MBI}$, empathy was positively correlated with PA but inversely associated with EE and DP, the other indicators of burnout.
Possible explanations for this include: (a) burnout reduces empathy; and (b) empathy prevents burnout ('job satisfaction'). ${ }^{(27)}$ The relationship between empathy and burnout is complex, but further investigation on the direct link between them was beyond the scope of this study.

Our data indicated that the relative contribution of empathy and burnout to each other may not be very large. The $r^{2}$ values derived from logistic regression analysis (EE: $r^{2}=0.035$; DP: $r^{2}=0.103$; PA: $r^{2}=0.200$ ) were small, suggesting that while empathy and burnout are related, there remains a large undefined component in their combined construct that is yet to be elucidated. We opine that empathy and burnout may be manifestations of the same personal-emotional construct. Further studies would be useful to understand the intricacies of empathy and burnout in the development of a resident's professionalism.

An interesting observation in our study was that empathy and burnout scores remained stable during residency training. This was in contrast to studies on US residents, where there was a trend of declining empathy as well as increasing fatigue and anger during the course of their training. ${ }^{(28)}$ The exact cause of this is unclear, and there may perhaps be certain cultural factors that are protective toward empathy decline and burnout. Alternatively, empathy decline and burnout may happen earlier even before residency, during training in medical school, and levels may have 'bottomed-out' by the time students graduate. In order to further elucidate this, we are continuing our longitudinal study from medical school to residency training.

To our knowledge, this was the first study in Singapore to evaluate empathy and burnout among residents. Our findings suggest that empathy is lower and burnout higher among our residents when compared to US residents. ${ }^{(1,11-13,29)}$ This is likely a reflection of multiple factors, ranging from medical education to work factors, such as hospital work-hours and policies, as well as societal expectations on physicians. Nevertheless, this issue is alarming, as empathy decline and high burnout can have serious repercussions for physicians' well-being and adversely affect quality of patient care. ${ }^{(9)}$

The US literature was used for our comparison because the majority of empathy and burnout literature on residents was based in the US. We also felt that the two training systems, that is, the local residency programme and the strict guidelines from the Accreditation Council for Graduate Medical Education in 
the US, were similar. This may allow us to hypothesise that reasons unrelated to training, such as local practices and cultural differences, were responsible for the disparity in results. Further examination of the hypothesis was, however, beyond the scope of the current study.

The main limitation of the present study was that it was conducted at a single sponsoring institution, restricting the generalisability of our results. Non-response may also have caused sampling errors and affected the results. We were unable to compare non-responders with responders, as the results were coded and anonymised, and the investigators were blinded. Nevertheless, our response rate was $50.7 \%$, similar to the typical rate of $52 \%$ reported for physician surveys. ${ }^{(30)}$ Cross-sectional investigations have shown no significant differences between responders and non-responders in physician survey studies. ${ }^{(31)}$ Finally, our questionnaire examined residents' recollections of experiences and therefore may have been susceptible to recall bias.

In summary, our findings suggest that empathy is lower and burnout higher among residents in Singapore when compared to their US counterparts. We also described the association between empathy and burnout. Further research into the underlying cause of this association is necessary in order to plan protective interventions.

\section{ACKNOWLEDGEMENTS}

This study was supported by an education research grant from the Academic Medicine Education Institute (AM.EI), Duke-NUS Medical School, Singapore. We would also like to thank Prof Sandy Cook, Senior Associate Dean, AM.El, who provided us with useful suggestions, Mr Samad Bin Asad, SingHealth Information Technology Department, who anonymised residents' data, programmed the electronic questionnaire and maintained the master list, Mr Shaw Yang Chia, statistician at National Heart Centre Singapore, who assisted in looking through the statistical analyses, and Ms Jeannie Lum, Programme Executive, SingHealth Cardiology Senior Residency Programme, who helped to liaise with other programme executives in the running of this study.

\section{REFERENCES}

1. Hojat M, Gonnella JS, Nasca TJ, et al. Physician empathy: definition, components, measurement, and relationship to gender and specialty. Am Psychiatry 2002; 159:1563-9.

2. Decety J, Meyer M. From emotion resonance to empathic understanding: a social developmental neuroscience account. Dev Psychopathol 2008; 20:1053-80.

3. Levinson W, Roter D. Physicians' psychosocial beliefs correlate with their patient communication skills. J Gen Intern Med 1995; 10:375-9.
4. Levinson W. Physician-patient communication. A key to malpractice prevention. JAMA 1994; 272:1619-20.

5. Suchman AL, Roter D, Green M, Lipkin M Jr. Physician satisfaction with primary care office visits. Collaborative Study Group of the American Academy on Physician and Patient. Med Care 1993; 31:1083-92.

6. Bertakis KD, Roter D, Putnam SM. The relationship of physician medical interview style to patient satisfaction. J Fam Pract 1991; 32:175-81.

7. Hojat M, Louis DZ, Markham FW, et al. Physicians' empathy and clinical outcomes for diabetic patients. Acad Med 2011; 86:359-64.

8. Shanafelt TD, Boone S, Tan L, et al. Burnout and satisfaction with work-life balance among US physicians relative to the general US population. Arch Intern Med 2012; 172:1377-85.

9. Shanafelt TD, Balch CM, Bechamps G, et al. Burnout and medical errors among American surgeons. Ann Surg 2010; 251:995-1000.

10. Spickard A Jr, Gabbe SG, Christensen JF. Mid-career burnout in generalist and specialist physicians. JAMA 2002; 288:1447-50.

11. Campbell J, Prochazka AV, Yamashita T, Gopal R. Predictors of persistent burnout in internal medicine residents: a prospective cohort study. Acad Med 2010; 85:1630-4.

12. Gelfand DV, Podnos YD, Carmichael JC, et al. Effect of the 80-hour workweek on resident burnout. Arch Surg 2004; 139:933-40.

13. Ripp J, Babyatsky M, Fallar R, Bazari H, Bellini L, Kapadia C, et al. The incidence and predictors of job burnout in first-year internal medicine residents: a fiveinstitution study. Acad Med 2011; 86:1304-10.

14. Shanafelt TD, Sloan JA, Habermann TM. The well-being of physicians. Am J Med 2003; 114:513-9.

15. Shanafelt TD, Balch CM, Dyrbye L, et al. Special report: suicidal ideation among American surgeons. Arch Surg 2011; 146:54-62

16. Brazeau CM SR, Rovi S, Boyd L. Relationships between medical student burnout, empathy and, professionalism climate. Acad Med 2010; 85(10 Suppl):S33-6.

17. Zenasni F, Boujut E, de Vaure B, et al. Development of a French-language version of the Jefferson Scale of Physician Empathy and association with practice characteristics and burnout in a sample of general practitioners. Int J Pers Cent Med 2012; 2:759-66.

18. Nielsen HG, Tulinius C. Preventing burnout among general practitioners: is there a possible route? Educ Prim Care 2009; 20:353-9.

19. Halpern J. What is clinical empathy? J Gen Intern Med 2003; 18:670-4.

20. Sng G, Tung J, Ping YS, et al. Complex and novel determinants of empathy change in medical students. Korean J Med Educ 2016; 28:67-78.

21. Ang SY, Dhaliwal SS, Ayre TC, et al. Demographics and personality factors associated with burnout among nurses in a Singapore tertiary hospital. Biomed Res Int 2016; 2016:696D184.

22. Hojat M. Empathy in Patient Care: Antecedents, Development, Measurement, and Outcomes. New York: Springer, 2007.

23. Maslach C, Jackson SE, Leiter MP. Maslach Burnout Inventory manual. Palo Alto, California: Consulting Psychologists Press, 1996

24. Maslach C, Jackson SE. The measurement of experienced burnout. J Occup Behav 1981; 2:99-113.

25. Kunyk D, Olson JK. Clarification of conceptualizations of empathy. J Adv Nurs $2001 ; 35: 317-25$

26. Carod-Artal FJ, Vazquex-Cabrera C. Burnout syndrome in an international setting. In: Bährer-Kohler S, ed. Burnout for Experts: Prevention in the Context of Living and Working. New York: Springer, 2013: 15-36.

27. Zenasni $F$, Boujut E, Woerner A, Sultan S. Burnout and empathy in primary care: three hypotheses. Br J Gen Pract 2012; 62:346-7.

28. Bellini LM, Shea JA. Mood change and empathy decline persist during three years of internal medicine training. Acad Med 2005; 80:164-7.

29. Di Lillo M, Cicchetti A, Lo Scalzo A, et al. The Jefferson Scale of Physician Empathy: preliminary psychometrics and group comparisons in Italian physicians. Acad Med 2009; 84:1198-202.

30. Cummings SM, Savitz LA, Konrad TR. Reported response rates to mailed physician questionnaires. Health Serv Res 2001; 35:1347-55.

31. Kellerman SE, Herold J. Physician response to surveys. A review of the literature. Am J Prev Med 2001; 20:61-7. 


\section{APPENDIX}

\section{Empathy Profiling of SingHealth Residents}

This information is strictly confidential and will be de-identified and aggregated for research purposes.

Name:

Date:

Nationality:

Marital status:

No. of children:

Religion:

Residency programme:

No. of post-graduate years:

\begin{tabular}{ll}
\hline & MCR no.: \\
& Age: \\
& Gender: \\
& No. of people in your household: \\
& No. of children aged $<5$ years: \\
& Do you employ domestic help? \\
& Year of residency: \\
& Medical school: \\
& Smoking (cigarette/day):
\end{tabular}

Average alcohol units/week:

Smoking (cigarette/day)

No. of years in Singapore:

On a scale of $1-5$, how much do you agree that these issues have affected your residency training over the past six weeks?

\begin{tabular}{|c|c|c|c|c|c|}
\hline \multirow[t]{2}{*}{ Issue } & $\begin{array}{l}\text { Strongly } \\
\text { disagree }\end{array}$ & & & & $\begin{array}{c}\text { Strongly } \\
\text { agree }\end{array}$ \\
\hline & 1 & 2 & 3 & 4 & 5 \\
\hline
\end{tabular}

\section{Structural/curricular factors}

1. Unstructured learning environments and training programmes

2. Inappropriate role models

3. Insufficient role models

5. Mistreatment by colleague

6. Vulnerability to patients' experiences (over-identification with patients, distress at patients' outcomes)

7. Inadequate peer support

8. High workload

9. Short patient hospital stay: difficult to empathise ('revolving door')

\section{Personal factors}

1. Burnout

2. Lower quality of life

3. Depression

4. Inadequate social support (family, friends)

5. Relationship issues (family, partner)

6. Financial pressures

7. Changing career goals

8. Changing training interests

9. Family planning (having children)

10. Victim of crime

\section{Specifics}

1. Your empathy levels declined over the past six months

2. Empathy levels among clinicians are lower than you expect

3. Thoughts or plans to move to private sector in the future

Further comments (optional): 